\title{
Genetic Analysis and Phenotypic Characterization of Effects on the Cytoskeleton of Coumarin-sensitivity Mutations in Dictyostelium discoideum
}

\author{
By DENNIS L. WELKER* AND KEITH L. WILLIAMS \\ Max-Planck-Institut für Biochemie, 8033 Martinsried bei München, \\ Federal Republic of Germany
}

(Received 30 July 1981; revised 22 September 1981)

\begin{abstract}
Five coumarin-sensitivity mutations were assigned to loci on three linkage groups: couB352 to group I; couC356, couE353 and couF354 to group II; and couD355 to group III. Coumarin inhibited cell division, affected cell shape and induced EDTA-sensitive cell-cell adhesion in vegetative cells at lower concentrations in coumarin-sensitive mutants $(1.0$ to $2.5 \mathrm{~mm}$ ) than in wild-type strains (3.0 mM). One mutant, HU609 (couB352), lysed in the presence of coumarin $(1.6 \mathrm{~mm})$. Coumarin, thiabendazole, and cambendazole induced multiple tips in pseudoplasmodia. Coumarin, unlike thiabendazole and cambendazole, did not induce metaphase arrest or haploidization of diploids. The couA351 and couF354 coumarin-sensitivity mutations are linked to growth temperature-sensitivity mutations, $t s g K 21$ and $t s g T 360$ respectively, which may be pleiotropic effects of the coumarin-sensitivity mutations. Exposure of vegetative cells of strains carrying either the couA351 or the couF354 mutation to the restrictive temperature $\left(28^{\circ} \mathrm{C}\right)$ induced cell rounding and cell-cell adhesion similar to that seen on treatment with coumarin. Wild-type strains, other coumarin-sensitive strains and other temperature-sensitive strains did not exhibit this phenotype at $28^{\circ} \mathrm{C}$. Furthermore, temperature-sensitivity and coumarin-sensitivity co-reverted in temperatureresistant derivatives selected from strains carrying the couA351/tsgK21 mutation.
\end{abstract}

\section{INTRODUCTION}

Coumarin is a naturally occurring compound found in many species of plants. Coumarin and its derivatives have a broad range of effects on fungi, bacteria, algae, plants and animals (for reviews, see Wolf, 1974; Feuer, 1974; Grigg, 1978; Cohen, 1979). Of relevance to the work reported here are the effects of coumarin on processes which involve microtubules. While we know of no direct evidence that coumarin binds to tubulin or microtubuleassociated proteins, it has been shown to induce metaphase arrest in cells of lily and onion (Cornman, 1947; Östergren, 1948). It also disrupts cell division and cell elongation in roots of wheat and corn, possibly by affecting the orientation of microtubules (Svensson, 1971). Other cytostatic and antifungal effects of coumarin have also been proposed to result from disruption of microtubules or microtubule organizing centres (Fasulo et al., 1979; Dall'Olio \& Vannini, 1979).

We have recently described a coumarin-sersitivity mutation (couA351) in Dictyostelium discoideum (Welker \& Williams, 1980c). Mutations affecting sensitivity to, or metabolism of, coumarin or its derivatives are known in other species, particularly mammals, including mouse (Lush \& Andrews, 1978) and man (O'Reilly \& Aggeler, 1965) where coumarin derivatives are used as anticoagulants. In this report we describe the isolation and genetic characterization of five additional coumarin-sensitivity mutations in $D$. discoideum. Such mutations may affect cytoskeletal proteins, coumarin metabolism, or the permeability of the 
plasma membrane to coumarin. Evidence is presented which indicates that the coumarinsensitivity of strains which carry the couA351 or couF354 mutations and a linked temperature-sensitivity ( $t s g K 21$ or $t s g T 360$, respectively) may be the pleiotropic effects of single mutations (on linkage groups VII and II, respectively). We also describe the effects of coumarin on cell division, cell shape and cell-cell adhesion in mutant and wild-type vegetative cells, and on the induction of multiple tips in pseudoplasmodia.

\section{METHODS}

Growth of amoebae. Stock cultures of Dictyostelium discoideum were maintained in association with a cobalt-resistant strain of Klebsiella aerogenes at $21 \pm 1{ }^{\circ} \mathrm{C}$ on SM agar plates (Williams, 1978).

Genetic analysis. Diploids were selected on the basis of complementation of temperature-sensitivity mutations ( $t$ sg) and mutations that lead to the inability to grow using Bacillus subtilis as a food source (bsg) (Newell et al., 1977). The restrictive temperature used for genetic analysis was $26.5 \pm 0.2{ }^{\circ} \mathrm{C}$. Complementation of the coumarin-sensitivity mutations was shown by selection of coumarin-resistant diploids on SM agar plates containing either 1.0 or $1.3 \mathrm{~mm}$-coumarin. For linkage analyses, haploid segregants were obtained from heterozygous diploids that had been plated clonally on SM agar plates containing the haploidizing agent benlate $\left(35 \mu \mathrm{g} \mathrm{ml}^{-1}\right.$ ) (Williams \& Barrand, 1978). The genotypes of the segregant haploids were determined using previously described techniques (Newell, 1978; Welker \& Williams, 1980c). The coumarin-sensitivity of segregant haploids was normally tested on SM agar plates containing 1.0 and $1.3 \mathrm{~mm}$-coumarin (Welker \& Williams, $1980 \mathrm{c}$ ). Some variation in toxicity of these media was observed. Therefore plating efficiencies varied somewhat with different batches of media; those presented were obtained from representative experiments and are given as the ratios of colony-forming ability on SM agar containing coumarin relative to that on SM agar without coumarin. Haploid strains used in this work are described in Table 1; all were derived from the NC4 wild-type strain.

Chemicals. Coumarin (1,2-benzopyrone), cycloheximide and isopropyl $N$-(3-chlorophenyl)carbamate (CIPC) were obtained from Sigma. Benlate was a gift from DuPont; methanol and cobaltous chloride were analytical reagent grade from May \& Baker. $N$-Methyl- $N^{\prime}$-nitro- $N$-nitrosoguanidine (MNNG) was obtained from Aldrich. Thiabendazole and cambendazole were gifts from William Bliss of Merck, Sharp \& Dohme, Research Labs, Ingleburn, N.S.W., Australia.

Mutagenesis. To induce coumarin-sensitivity or temperature-sensitivity mutations, amoebae of the haploid

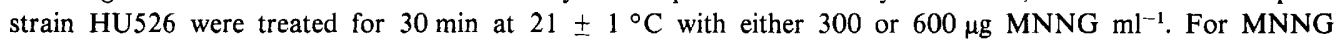
treatment, vegetative cells were harvested from SM agar plates, the bacteria were removed by differential centrifugation and the cells were resuspended in phosphate-buffered saline (PBS; Deering et al., 1970) at 10 amoebae $\mathrm{ml}^{-1}$. Following mutagenesis the cells were washed three times by centrifugation and then inoculated on SM agar plates to obtain colonies from the surviving cells. Survival was $12 \%$ after treatment with $300 \mu \mathrm{g}$ MNNG

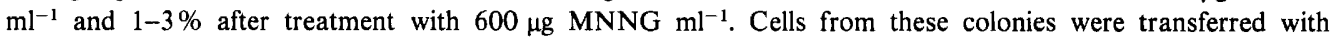
toothpicks to SM agar plates containing $1.0 \mathrm{mM}$-coumarin, or to SM agar plates which were then incubated at $26.5 \pm 0.2^{\circ} \mathrm{C}$, in order to isolate coumarin-sensitive or temperature-sensitive mutants, respectively. Colonies unable to grow under these conditions were retested after cloning from the original plates which had been stored at $4{ }^{\circ} \mathrm{C}$ during the initial screening period.

Selection of temperature-resistant revertants. Revertants were selected from strains bearing the tsgK21/ couA351 mutation(s) by plating between $10^{4}$ and $10^{5}$ amoebae or spores on SM agar plates in association with $K$. aerogenes and then allowing the cells to multiply at the permissive growth temperature $\left(21^{\circ} \mathrm{C}\right)$ for about $2 \mathrm{~d}$. When extensive growth was visible but prior to clearing of the bacterial lawn, the plates were shifted to the restrictive temperature $\left(26.5^{\circ} \mathrm{C}\right)$. Plaques appeared on these plates over the next week. Usually one or two revertants were found per plate. Cells from these colonies were cloned once at $26.5^{\circ} \mathrm{C}$ and subsequently handled at $21^{\circ} \mathrm{C}$.

Treatment with coumarin and mitotic inhibitors in suspension cultures. Cells were grown overnight in suspension cultures (5-15 $\mathrm{ml}$ in $125 \mathrm{ml}$ Erlenmeyer flasks) with Escherichia coli $\mathrm{B} / \mathrm{r}$ (about $10^{10}$ bacteria $\mathrm{ml}^{-1}$ ) in PBS at $180 \mathrm{rev} \cdot \mathrm{min}^{-1}$ on a Kühner Lab-Shaker at $21 \pm 1{ }^{\circ} \mathrm{C}$. The exponentially growing culture was then divided into control and drug-treatment cultures, diluted to between $10^{5}$ and $5 \times 10^{5}$ cells ml ${ }^{-1}$ by the addition of fresh $E$. coli $\mathrm{B} / \mathrm{r}$ suspension in PBS and returned to the shaker. Coumarin stock solutions ( 5 to $15 \mathrm{~mm}$ ) were sterilized by autoclaving in PBS. Thiabendazole, cambendazole and CIPC stocks at $20 \mathrm{mg} \mathrm{m}^{-1}$ were prepared in dimethyl sulphoxide and stored at $-20^{\circ} \mathrm{C}$. The drug solutions were added directly to the suspension cultures to give the final drug concentrations required. In control cultures, concentrations of dimethyl sulphoxide as high as $4.0 \%$ (v/v) had no effect on doubling time or cell-cell adhesion. Samples were removed during the course of the drug treatment to determine cell densities using a haemocytometer. Cell shape and cell-cell adhesion were observed in 


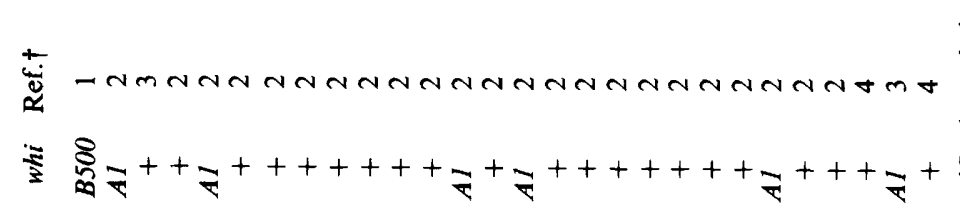

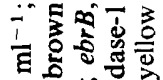

o

距

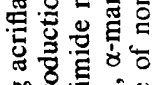

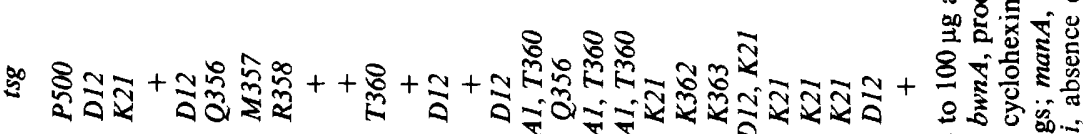

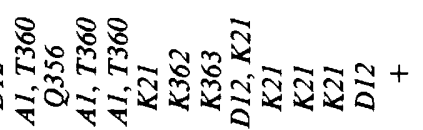

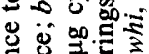

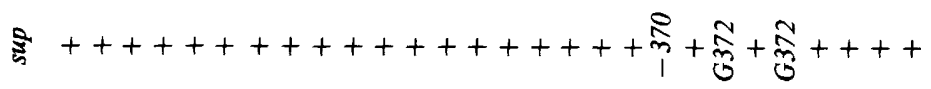

要解.

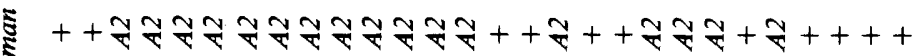

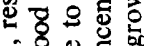

年 \&

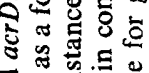

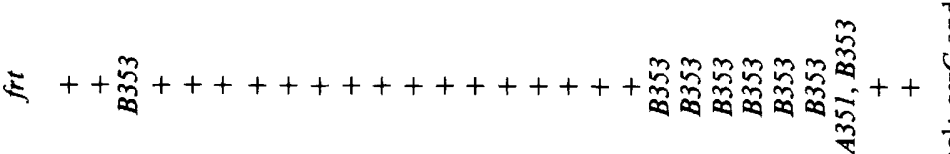

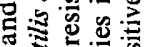

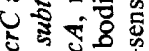

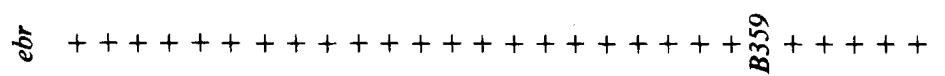

8 डे

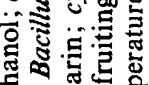

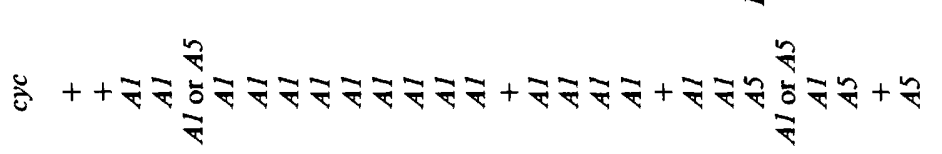

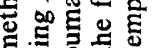

$$
\text { \& }+++7++++++++++++++++++++ \text { ₹ ₹ }
$$
50

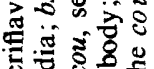

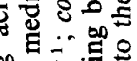

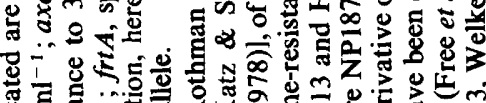


these samples. In some experiments drug-free cultures were prepared as above and then shifted to $28 \pm 1{ }^{\circ} \mathrm{C}$ to determine the effects of exposure to restrictive temperatures $\left(26.5^{\circ} \mathrm{C}\right.$ and above $)$ on cell division, cell shape and cell-cell adhesion.

Formation of isogenic diploids. Cells of haploid strains grown overnight in suspension cultures were diluted to about $10^{6} \mathrm{ml}^{-1}$ and exposed for $8 \mathrm{~h}$ to $10 \mu \mathrm{g}$ thiabendazole $\mathrm{ml}^{-1}$ in PBS in the presence of about $10^{10} \mathrm{E}$. coli $\mathrm{B} / \mathrm{r}$ $\mathrm{ml}^{-1}$ at $21^{\circ} \mathrm{C}$ as described by Welker \& Williams $(1980 \mathrm{~b})$. Survival, as determined by colony-forming ability on SM agar after this treatment, was about $20 \%$ and approximately $50 \%$ of the colonies were diploid.

Multiple tip formation in drug-treated pseudoplasmodia. Cells were removed from the growing edge of colonies and inoculated on water agar plates which contained $1.5 \%(\mathrm{w} / \mathrm{v})$ Difco agar and $250 \mu \mathrm{g}$ dihydrostreptomycin sulphate $\mathrm{ml}^{-1}$. The plates were placed in opaque PVC boxes with lateral light sources at $21 \pm 1^{\circ} \mathrm{C}$ and the cells were allowed to aggregate to form pseudoplasmodia which migrated towards the light source. Migrating pseudoplasmodia were removed from these plates by lifting them off the agar surface by their slime trails, transferred to inhibitor-containing water agar plates, and returned to the PVC boxes with lateral light sources for further migration. The concentrations of inhibitors used were: coumarin, 1.0-2.0 mM; thiabendazole, $30-50 \mu \mathrm{g}$ $\mathrm{ml}^{-1}$; cambendazole, $80-100 \mu \mathrm{g} \mathrm{ml}^{-1}$; CIPC, $10 \mu \mathrm{g} \mathrm{ml}^{-1}$. Coumarin was added prior to autoclaving the agar; all other inhibitors were added to sterilized molten agar prior to pouring the plates.

Scanning electron microscopy. Scanning electron micrographs were kindly produced for us by Dr M. Claviez and Frau A. Röglin using cells that had been grown and treated with inhibitors in suspension cultures as described above. Samples were fixed for electron microscopy with glutaraldehyde and osmium tetroxide. The fixation technique used was that of Drs G. Gerisch and R. Guggenheim and will be described by them elsewhere.

\section{RESULTS}

Isolation of coumarin-sensitive and growth temperature-sensitive mutants

Following MNNG mutagenesis of strain HU526, three coumarin-sensitive mutants (HU609, HU610 and HU612), two temperature-sensitive mutants (HU606 and HU607) and two mutants that were both coumarin-sensitive and temperature-sensitive (HU608 and HU611) were isolated from a total of 1300 colonies screened. Thus, it appears that coumarin-sensitive mutants can be isolated at frequencies similar to those at which temperature-sensitive mutants are found.

Plating efficiencies, relative to that on SM agar, at coumarin concentrations between 0.5 and $1.3 \mathrm{~mm}$ were determined for each of the coumarin-sensitive mutants and also their parent, HU526 (Table 2). At $1.3 \mathrm{mm-coumarin,} \mathrm{HU526}$ and other wild-type strains had plating efficiencies of 1.0 , while those of coumarin-sensitive mutants ranged from $3 \times 10^{-3}$ to less than $10^{-6}$ (Table 2; Welker \& Williams, 1980c).

\section{Genetic analysis of the coumarin-sensitivity mutations}

Four of the new coumarin-sensitivity mutations (couB352, couD355, couE353, couF354) are recessive since mutants carrying them formed coumarin-resistant diploids when crossed to the wild-type haploid X23 (Table 3). However, the couC356 mutation is semi-dominant (Table 3). Complementation tests in which coumarin-sensitive haploid strains were crossed to form heterozygous diploids indicated that the five new coumarin-sensitivity mutations and also the couA351 mutation each affect a different locus (Table 3). In all cases coumarin-resistant diploid colonies were isolated from SM agar plates containing either 1.0 or $1.3 \mathrm{~mm}$-coumarin after allowing parasexual cell fusion to occur. These experiments were performed at $21 \pm 1^{\circ} \mathrm{C}$. Thus, complementation of coumarin-sensitivity mutations is an effective method for the selection of heterozygous diploids at permissive growth temperatures.

The couA351 mutation has been assigned previously to linkage group VII (Welker \& Williams, $1980 \mathrm{c}$ ). Parasexual genetic analyses indicated that the newly isolated coumarinsensitivity mutations map to three of the other six linkage groups. The couB352 (HU609) mutation was assigned to linkage group I on the basis of its segregation with the $c y c A 1$ (cycloheximide-resistance) mutation (Table 4). The couC356 (HU608), couE353 (HU610) and couF354 (HU611) mutations were assigned to linkage group II on the basis of their segregation relative to mutations at the whiA (spore colour), $\operatorname{tsg} D$ (temperature-sensitivity) 
Table 2. Plating efficiencies of wild-type and coumarin-sensitive strains on SM agar plates containing coumarin relative to that on SM agar without coumarin

\begin{tabular}{lccccc} 
& & \multicolumn{4}{c}{ Relative plating efficiency } \\
\cline { 3 - 7 } Strain & Mutation & 0.5 & 0.75 & 1.0 & 1.3 \\
HU526 & + & 1.0 & 1.0 & 1.2 & 1.1 \\
HU608 & couC356 & $7.0 \times 10^{-2}$ & $7.3 \times 10^{-5}$ & $<10^{-6}$ & $<10^{-6}$ \\
HU609 & couB352 & $3.4 \times 10^{-3}$ & $3.0 \times 10^{-4}$ & $1.3 \times 10^{-5}$ & $<10^{-6}$ \\
HU610 & couE353 & $9.8 \times 10^{-1}$ & $8.3 \times 10^{-1}$ & $5.1 \times 10^{-1}$ & $3.0 \times 10^{-3}$ \\
HU612 & couD355 & $9.3 \times 10^{-1}$ & $8.8 \times 10^{-1}$ & $2.0 \times 10^{-4}$ & $9.5 \times 10^{-6}$ \\
HU876* & couF354 & $9.2 \times 10^{-1}$ & $6.9 \times 10^{-1}$ & $1.0 \times 10^{-2}$ & $1.1 \times 10^{-3}$ \\
NP187 & couA351 & $6.2 \times 10^{-1}$ & $6.6 \times 10^{-3}$ & $3.5 \times 10^{-5}$ & $1.0 \times 10^{-6}$
\end{tabular}

* The original couF354 coumarin-sensitive mutant, HU611, has a low plating efficiency (about $10^{-4}$ ) on SM agar without coumarin, presumably due to a second mutation not linked to the couF354 mutation.

All strains in this table had a colony-forming ability in excess of $50 \%$ on SM agar. The plating efficiencies presented in this table and earlier work (Welker \& Williams, 1980c) were obtained on SM agar prepared using Bacto-peptone from Difco. All others were obtained using media prepared with Oxoid bacteriological peptone which consistently gave higher plating efficiencies.

\section{Table 3. Complementation tests involving coumarin-sensitivity mutations}

Diploidy was determined on the basis of spore size and, if applicable, the complementation of recessive mutations other than coumarin-sensitivity mutations. An $\mathrm{S}$ denotes non-complementation (plating efficiency less than 0.01 on SM agar containing $1.3 \mathrm{~mm}$-coumarin); an $\mathbf{R}$ denotes complementation (plating efficiency close to 1.0 except for diploids heterozygous for the semidominant couC356 mutation where the plating efficiencies were in the range of 0.1 to 0.35 on SM agar containing 1.3 mM-coumarin).

$\begin{array}{cccccc}\mathrm{NP187} & \mathrm{HU609} & \text { HU608 } & \text { HU612 } & \text { HU610 } & \text { HU611 } \\ (\text { couA35I }) & (\text { couB352 }) & (\text { couC356) } & (\text { couD355) } & (\text { couE353) } & (\text { couF354 })\end{array}$

NP187 (couA351)

HU609 (couB352)

S (DU1869)*

HU608 (couC356)

R (DU950)

HU612 (couD355)

R (DU932)

HU610 (couE353)

R (DU953)

R (DU930)

R (DU1197)†

HU611 (couF354)

R (DU931)

R (DU973)

R (DU1112)

R (DU974)

R (DU2025)

R (DU984)

R (DU1111)

R (DU1085)

R (DU1052)

R (DU1015)

R (DU1018) R (DU972)

$\mathrm{X} 23\left(\mathrm{cou}^{+}\right)$

R (DU1089)

R (DU1088)

R (DU1086) R (DU1118)

* Since all coumarin-sensitivity mutations complemented, the couA351 mutation was made homozygous by chromosome-doubling using thiabendazole (Welker \& Williams, $1980 \mathrm{~b}$ ). The sensitivity of DU1869 constructed in this manner demonstrates that there is no ploidy-specific effect on coumarin-sensitivity, i.e. that homozygous alleles are non-complementing. Further evidence that homozygous coumarin-sensitivity mutations do not complement was obtained with diploids (DU1678 and DU1689) homozygous for the couA351 mutation which were constructed by standard parasexual techniques based on complementation of $B$. subtilis-sensitivity mutations at $21^{\circ} \mathrm{C}$. DU1678 (HU1016/HU1091) and DU1689 (HU1148/HU1091) were also heterozygous for the sup-370 and supG372 mutations which suppress the couA351 coumarin-sensitivity. Thus, sup-370 and supG372 must be recessive.

† The parental haploids of DU1197 were HU608 and HU795 (couB352); all other diploids were constructed by fusion of the haploids shown.

and/or acrA (methanol-resistance) loci (Table 4). The couD355 (HU612) mutation was assigned to linkage group III on the basis of its segregation with the bsgA5 ( $B$. subtilis-sensitivity) mutation (Table 4). In all cases, the coumarin-sensitivity mutations were found to segregate independently of markers on the five linkage groups to which they were not assigned (Table 4). 
Table 4. Genotypes of haploid segregants derived from diploids heterozygous for coumarinsensitivity mutations

Diploid

(Parental haploids)

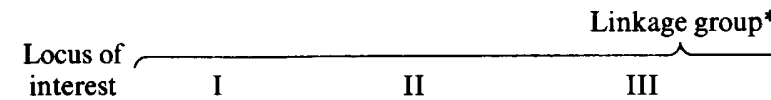

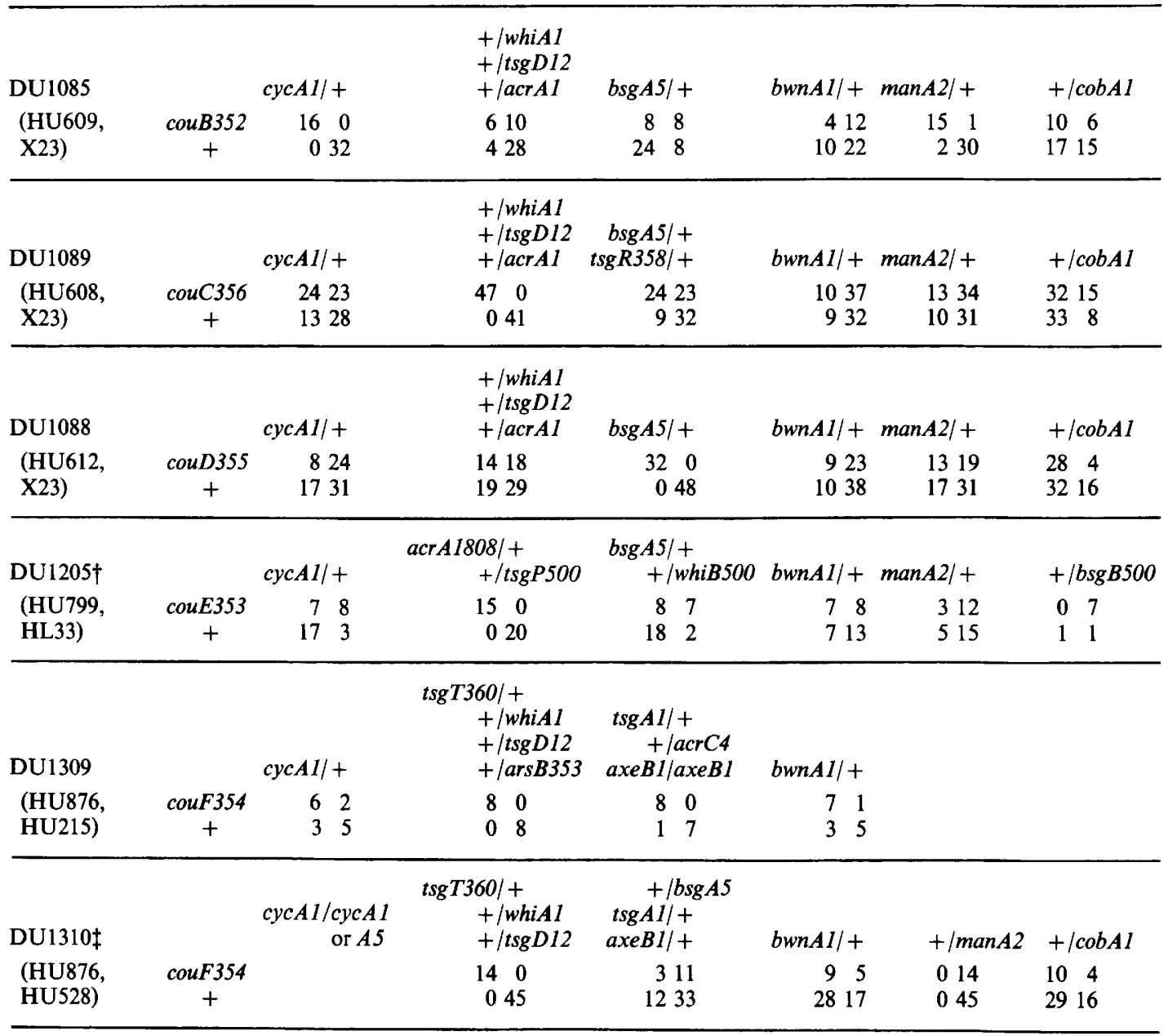

* Linkage group $\mathrm{V}$ remains to be established genetically.

$\dagger$ The presence of the bsgB500 mutation was scored only in segregants that did not carry the $b s g A 5$ mutation.

$\ddagger$ All segregants of DU1310 were cycloheximide-resistant. DU1310 was heterozygous at the manA locus but only segregants carrying the manA2 allele were obtained. It is possible that the chromosome carrying the man $^{+}$allele may have acquired a recessive-lethal mutation.

No evidence for the presence of suppressor mutations like sup-370 or supG372 was found with these diploids.

\section{Genetic analysis of the temperature-sensitivity mutations}

Since three of the six coumarin-sensitive mutants isolated in D. discoideum (NP187, HU608 and HU611) acquired a growth temperature-sensitivity in the same mutagenesis that produced the coumarin-sensitivity, it was important to attempt to determine whether or not the coumarin-sensitive and temperature-sensitive phenotypes were the pleiotropic effect of a single genetic lesion. With strain NP187 we have shown previously that the coumarinsensitivity and temperature-sensitivity are both on linkage group VII (Welker \& Williams, 
Table 5. Genotypes of haploid segregants derived from diploids heterozygous for temperaturesensitivity mutations

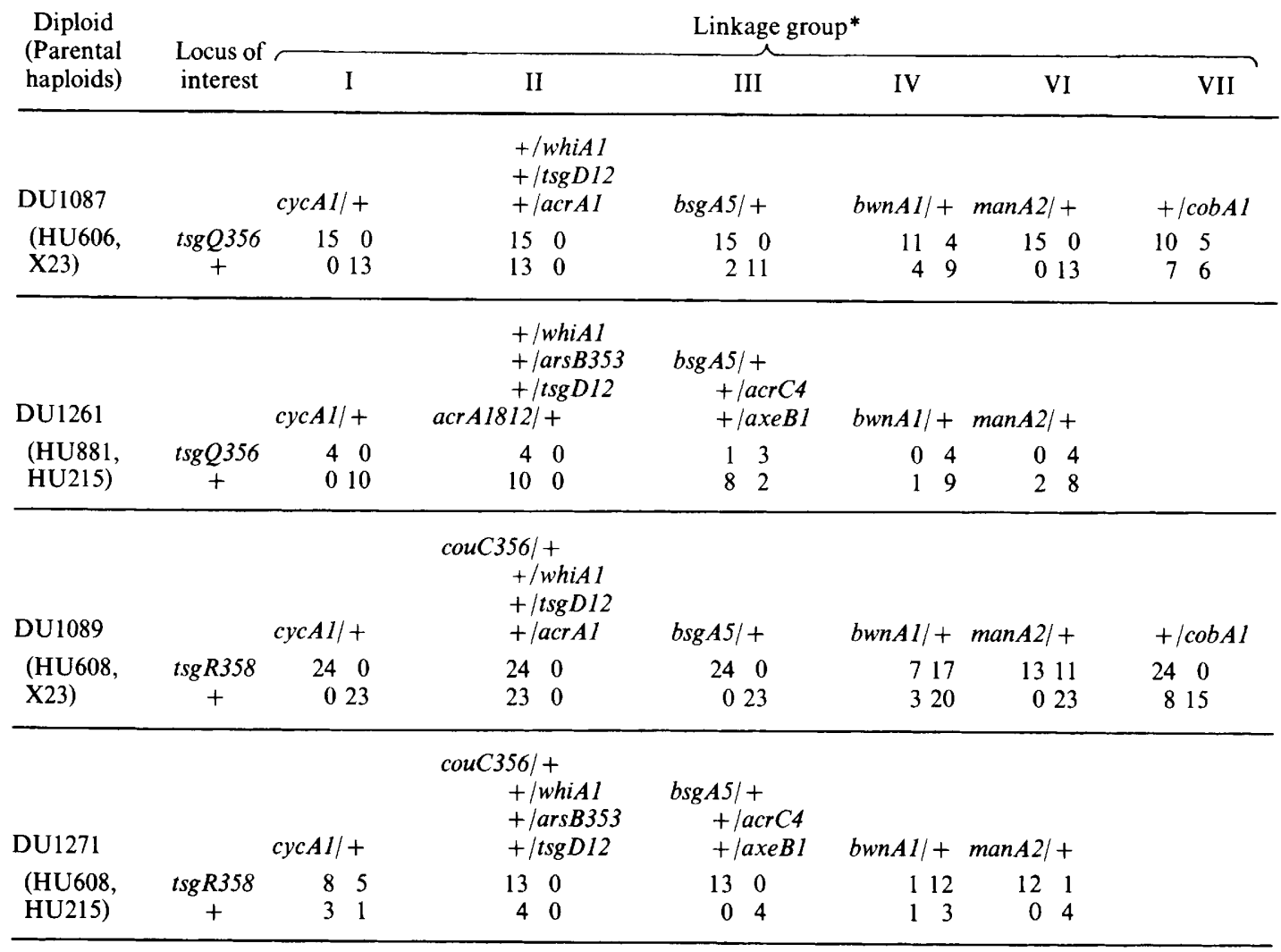

* Linkage group $\mathrm{V}$ remains to be established genetically.

Only data obtained with yellow, $t s g D^{+}$segregants is presented. White, temperature-sensitive $(t s g D 12)$ segregants were obtained in all segregations but were excluded from the data presented since the $t s g Q 356$ and $t s g R 358$ mutations would be masked by the presence of the $t s g D 12$ mutation.

Cosegregation of linkage groups I and III (and VI) occurred in the segregants of DU1087 and DU1089. Similar linkage associations have been seen previously in $D$. discoideum (Welker \& Williams, $1980 \mathrm{c}$ ).

$1980 c$ ); thus, they may be the pleiotropic effects of a single mutation. Since the coumarin-sensitivity of strain HU611 (couF354) mapped to linkage group II (Table 4), a diploid (DU1363) which was heterozygous for coumarin-sensitivity, temperature-sensitivity and methanol-resistance (couF354 tsgT360 acrA1814/couF $\mathrm{tsgT}^{+} \mathrm{acrA}^{+}$) was constructed to test for linkage of the coumarin-sensitivity and temperature-sensitivity on the basis of mitotic recombination (or non-disjunction). Four independently isolated methanol-resistant diploids selected from $8 \times 10^{5}$ cells of DU1363 were coumarin-sensitive and temperaturesensitive (couF354 tsgT360 acrA1814/couF354 tsgT360 acrA1814). Thus, both the coumarin-sensitivity (couF354) and temperature-sensitivity (tsgT360) of strain HU611 and its derivatives map to linkage group II and could be the pleiotropic effects of a single mutation. The $t s g R 358$ mutation of strain HU608 was assigned to linkage group III on the basis of its segregation with the bsgA5 mutation and segregation independent of markers on linkage groups I, II, IV, VI and VII (Table 5). However, strains that carried the linkage group II bearing the couC356 mutation, but no known temperature-sensitivity mutation, had plating efficiencies of 0.006 to 0.3 at $26.5^{\circ} \mathrm{C}$. Thus, the $t s g R 358$ and couC356 mutations certainly 
Table 6. Plating efficiencies at $26.5^{\circ} \mathrm{C}$ and on $S M$ agar containing coumarin of strains bearing the tsgK21/couA351 mutation(s) and of revertants derived from them on the basis of temperature-resistance

\begin{abstract}
The revertants are of certain independent origin except for the pair HU1017 and HU1018 and the pair HU1166 and HU1167. These pairs of revertants are probably of independent origin also since they are phenotypically different. The plating efficiencies are given as the ratio of colony-forming ability under the restrictive condition relative to that at $21{ }^{\circ} \mathrm{C}$ on SM agar. Two of these revertants, HU1195 and HU1196, are also altered in development, having smaller sori and thinner stalks than their parent NP187.
\end{abstract}

\begin{tabular}{|c|c|c|c|c|}
\hline \multirow[b]{2}{*}{ Strain } & \multirow[b]{2}{*}{ Parent } & \multicolumn{3}{|c|}{ Relative plating efficiency } \\
\hline & & At $26 \cdot 5^{\circ} \mathrm{C}$ & $\begin{array}{l}\text { With } 1.0 \mathrm{mM}^{-} \\
\text {coumarin }\end{array}$ & $\begin{array}{l}\text { With } 1.3 \mathrm{~mm}- \\
\text { coumarin }\end{array}$ \\
\hline $\begin{array}{l}\text { HU413 } \\
\text { HU1168 } \\
\text { NP187 }\end{array}$ & $\begin{array}{l}- \\
- \\
-\end{array}$ & $\begin{array}{l}<10^{-5} \\
<10^{-5} \\
<10^{-5}\end{array}$ & $\begin{array}{c}3.0 \times 10^{-2} \\
1.5 \times 10^{-3} \\
0.4\end{array}$ & $\begin{aligned} & <10^{-5} \\
& <10^{-5} \\
5 & \times 10^{-4}\end{aligned}$ \\
\hline HU1017 & HU413 & $0 \cdot 4$ & $1 \cdot 1$ & $0 \cdot 2$ \\
\hline HU1018 & HU413 & $0 \cdot 7$ & $1 \cdot 1$ & $1 \cdot 0$ \\
\hline HU1202 & HU413 & $0 \cdot 5$ & $0 \cdot 8$ & $6 \times 10^{-3}$ \\
\hline HU1203 & HU413 & $3 \times 10^{-2}$ & $0 \cdot 8$ & $4 \times 10^{-3}$ \\
\hline HU1200 & HU1168 & $0 \cdot 1$ & $1 \cdot 0$ & 0.3 \\
\hline HU1166 & NP187 & $1 \cdot 0$ & $1 \cdot 0$ & $1 \cdot 0$ \\
\hline HU1167 & NP187 & $0 \cdot 1$ & $0 \cdot 7$ & $0 \cdot 3$ \\
\hline HU1193 & NP187 & $0 \cdot 3$ & $1 \cdot 1$ & $0 \cdot 7$ \\
\hline HU1195 & NP187 & $0 \cdot 4$ & $1 \cdot 0$ & $0 \cdot 5$ \\
\hline HU1196 & NP187 & 0.5 & $0 \cdot 9$ & 0.7 \\
\hline HU1197 & NP187 & $0 \cdot 1$ & 0.9 & $0 \cdot 4$ \\
\hline HU1198 & NP187 & $0 \cdot 1$ & $1 \cdot 0$ & $0 \cdot 7$ \\
\hline HU1199 & NP187 & $0 \cdot 1$ & $1 \cdot 1$ & 0.6 \\
\hline
\end{tabular}

affect different loci but there may also be a slight temperature-sensitivity associated with the couC356 mutation.

The tsgQ356 mutation of strain HU606, which was isolated at the same time as the coumarin-sensitive mutants, was assigned to linkage group I on the basis of its segregation with the cycA1 mutation and segregation independent of markers on linkage groups II, III, IV, VI and VII (Table 5). The tsgM357 mutation of strain HU607 was mapped to linkage group VII (Welker \& Williams, 1980c).

\title{
Co-reversion of the temperature-sensitivity and coumarin-sensitivity in temperature-resistant revertants of strains that carry the tsgK21/couA351 mutation(s)
}

Evidence supporting the hypothesis that the $t s g K 21$ temperature-sensitivity and couA351 coumarin-sensitivity are the pleiotropic effects of a single mutation was obtained with putative revertants selected on the basis of temperature-resistance from strains NP187, HU413 and HU1168. All eleven independently isolated temperature-resistant derivatives (seven from NP187, one from HU1168 and three from HU413) were more resistant to coumarin than their parents (Table 6). Most of these strains clearly did not have wild-type phenotypes, since they had lower colony-forming ability at $26.5{ }^{\circ} \mathrm{C}$ and on media containing coumarin than at $21^{\circ} \mathrm{C}$ on SM agar (Table 6). Genetic analysis of putative revertants of strain HU413 (HU1017 and HU1018, which may not be of independent origin) gave results consistent with either a reversion at the $t \mathrm{sg} K / \operatorname{couA}$ locus or with another mutation on linkage group VII that suppresses both the growth temperature-sensitivity and coumarin-sensitivity (data not shown). If such a suppressor mutation exists in HU1017 or HU1018, it must be dominant, since heterozygous diploids formed by fusion of NP187 with HU1017 or HU1018 were 
selected at the restrictive temperature $\left(26.5^{\circ} \mathrm{C}\right)$. These diploids, DU1489 and DU1433, respectively, which arose at a lower than normal frequency, had plating efficiencies of only about 0.01 at $26.5^{\circ} \mathrm{C}$ and 0.20 on SM agar containing $1.3 \mathrm{~mm}$-coumarin. The low plating efficiencies of these diploids are consistent with the partial reversion of the temperaturesensitivity and coumarin-sensitivity seen in the haploid revertants. In comparison, homozygous tsgK21/couA351 diploids formed by chromosome doubling of HU413 (DU1850) and NP187 (DU1869) had plating efficiencies at $26.5^{\circ} \mathrm{C}$ of less than $10^{-6}$ and on SM agar containing $1.3 \mathrm{~mm}$-coumarin of about 0.003 and 0.01 , respectively. Plating efficiencies for HU413 and NP187, determined concurrently with those of DU1850 and DU1869, were similar to those of DU1850 and DU1869, respectively.

The coumarin-sensitivity, but not the growth temperature-sensitivity, of derivatives of strain NP187 can certainly be suppressed by mutations at loci other than couA. We have evidence for at least two such mutations (sup-370 and sup G372) which do not map on linkage group VII. Strains carrying the $t s g K 21$ mutation in the presence of either of these suppressor mutations remain temperature-sensitive. Strains HU1016 (sup-370 tsgK21/couA351) and HU1148 (supG372 tsgK21/couA351) had plating efficiencies on SM agar at $26.5{ }^{\circ} \mathrm{C}$ of less than $10^{-6}$ but of about 1.0 on SM agar containing $1.3 \mathrm{mM}$-coumarin. Both the sup-370 and supG372 mutations are recessive since diploids (DU1678 and DU1689, respectively) constructed by fusion of HU1016 and HU1148 with strain HU1091 (couA351/tsgK21) were temperature-sensitive and had plating efficiencies on SM agar-containing $1.3 \mathrm{mM}$-coumarin of about 0.002 and 0.01 , respectively. Many of the colonies which did appear on plates containing $1.3 \mathrm{~mm}$-coumarin with these diploids were actually haploid segregants that bore the suppressor mutation.

Coumarin-resistance may arise from second-site mutations that affect membrane permeability but which leave the original mutation unaffected, while selection for temperature-resistance may be more stringent and lead to the isolation only of strains able to grow both at the restrictive temperature and in the presence of coumarin. The supG372 mutation probably does affect the permeability of the cell membrane since, in addition to increased resistance to coumarin, strains bearing this mutation have decreased resistance to cycloheximide and acriflavine. The supG372 mutation was discovered in the genetic analysis of strain HU1018, a temperature-resistant revertant of strain HU413. It must have arisen during the isolation of this strain since the parent of HU1018 (HU413) does not carry the supG372 mutation. We suggested previously that the $t s g K 21$ and couA351 mutation(s) affected different loci (Welker \& Williams, 1980c) on the basis of strains which were coumarin-resistant but temperature-sensitive. These findings can be explained by the presence of suppressor mutations like supG372 rather than reversion of a coumarin-sensitivity mutation alone.

\section{Inhibition of cell division by coumarin}

We have shown previously that wild-type cells of $D$. discoideum have little or no loss of colony-forming ability on SM media containing 1.0 or $1.3 \mathrm{~mm}$-coumarin (Welker \& Williams, $1980 c$; see also Table 2). However, we observed that the growth rate was decreased on media containing coumarin; specifically, colonies appeared later and expanded more slowly in the presence of coumarin. The effect of coumarin on wild-type and coumarinsensitive strains was investigated further in suspension culture in the presence of pregrown bacteria. This procedure eliminates any effects which coumarin might have on bacterial growth and allows changes in cell number to be easily determined.

The doubling times of cells of the wild-type strain, HU526, were found to increase with increasing concentrations of coumarin between 1.0 and $2.5 \mathrm{~mm}$. At concentrations of 1.0 and $1.3 \mathrm{mM}$-coumarin the doubling times were about 4.5 and $5.5 \mathrm{~h}$, respectively, while that of the untreated control culture was less than $4.0 \mathrm{~h}$. Concentrations of $2.5 \mathrm{~mm}$, or more, 


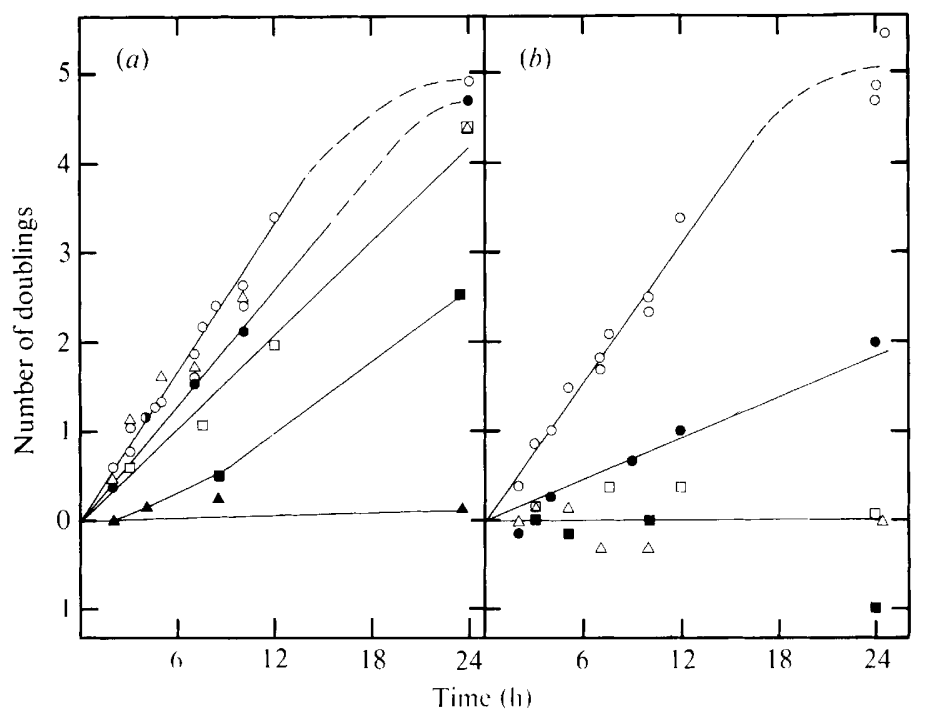

Fig. 1. Growth curves of the wild-type coumarin-resistant haploid HU526 (a) and of the couA351 coumarin-sensitive haploid HU413 (b) in PBS in the presence of about $10^{10} \mathrm{E}$. coli $\mathrm{B} / \mathrm{r} \mathrm{m}{ }^{-1}$ under illumination with rotation at $180 \mathrm{rev} . \mathrm{min}^{-1}$. Cells were treated at $21 \pm 1{ }^{\circ} \mathrm{C}$ with no coumarin $(O)$,

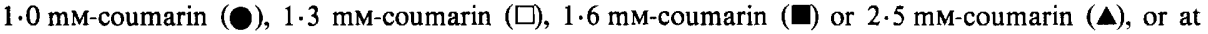
$28 \pm 1{ }^{\circ} \mathrm{C}(\triangle)$.

\section{Table 7. Cell-cell adhesion induced by different treatments}

Cell-cell adhesion was assayed in PBS in the presence of about $10^{10} \mathrm{E}$. coli $\mathrm{B} / \mathrm{r} \mathrm{ml}^{-1}$. Cell suspensions $(5 \mathrm{ml})$ were rotated under illumination at $180 \mathrm{rev} . \mathrm{min}^{-1}$. In all cases, cell division was completely inhibited by these treatments and the treated cells became spherical. Untreated control cells prepared and handled similarly were irregular in shape and continued to divide. Less than $5 \%$ of control cells were in contact prior to the stationary phase (18-24 h). Adhesion was observed in some experiments at lower coumarin concentrations than those given here; with lower coumarin concentrations longer times were required before adhesion was observed and fewer cells were involved. At higher concentrations adhesion was seen earlier and a greater percentage of the cells were involved. The number of cells in any one group varied from two to ten or more but pairs were the most common type seen. The data presented are from representative experiments. The times of assay varied from strain to strain within the stated limits. Cell-cell adhesion was not seen with HU609 (couB352); this strain lysed when exposed to $1.6 \mathrm{~mm}$-coumarin.

Strain Treatment $\quad \overbrace{\begin{array}{c}\text { Duration of treatment: } \\ 2-3 \mathrm{~h} \quad 4.5-6 \mathrm{~h} \quad 8 \cdot 5-10 \mathrm{~h} \quad 23-24 \cdot 5 \mathrm{~h}\end{array}}^{\begin{array}{c}\text { Cell-cell adhesion } \\ \text { (percentage of cells in contact) }\end{array}}$

HU526 $\left(\right.$ cou $\left.^{+}\right)$
HU526 $\left(\right.$cou $\left.^{+}\right)$
HU526 $\left(\right.$cou $\left.^{+}\right)$
HU526 $\left(\right.$cou $\left.^{+}\right)$
HU413 $($couA35I)
HU413 (couA35I)
HU608 (couC356)
HU833 (couD355)
HU610 (couE353)
HU970 (couF354)
HU970 (couF354)

$3 \cdot 0 \mathrm{~mm}$-coumarin

$50 \mu \mathrm{g}$ thiabendazole $\mathrm{ml}^{-1}$

$100 \mu \mathrm{g}$ cambendazole $\mathrm{ml}^{-1}$

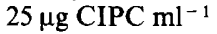

$1.6 \mathrm{~mm}$-coumarin

$28^{\circ} \mathrm{C}$

$1.0 \mathrm{~mm}$-coumarin

$2.5 \mathrm{~mm}$-coumarin

1.6 mM-coumarin

$1.6 \mathrm{~mm}$-coumarin

$28{ }^{\circ} \mathrm{C}$

$\begin{array}{rccc}64 & - & 79 & - \\ 45 & 33 & - & - \\ 69 & - & - & - \\ 78 & 79 & 73 & - \\ 3 & 10 & 89 & 66 \\ 25 & 70 & >95 & 46 \\ 45 & 45 & 20 & - \\ 57 & 64 & 78 & 89 \\ <5 & 30 & 65 & 50 \\ <5 & 56 & 52 & 31 \\ <5 & <5 & 36 & 70\end{array}$

completely inhibited cell division (Fig. 1a). Similar effects were seen with all strains carrying mutations that lead to coumarin-sensitivity. The major difference between these mutants and wild-type strains was that cell division of the coumarin-sensitive strains was inhibited at lower 

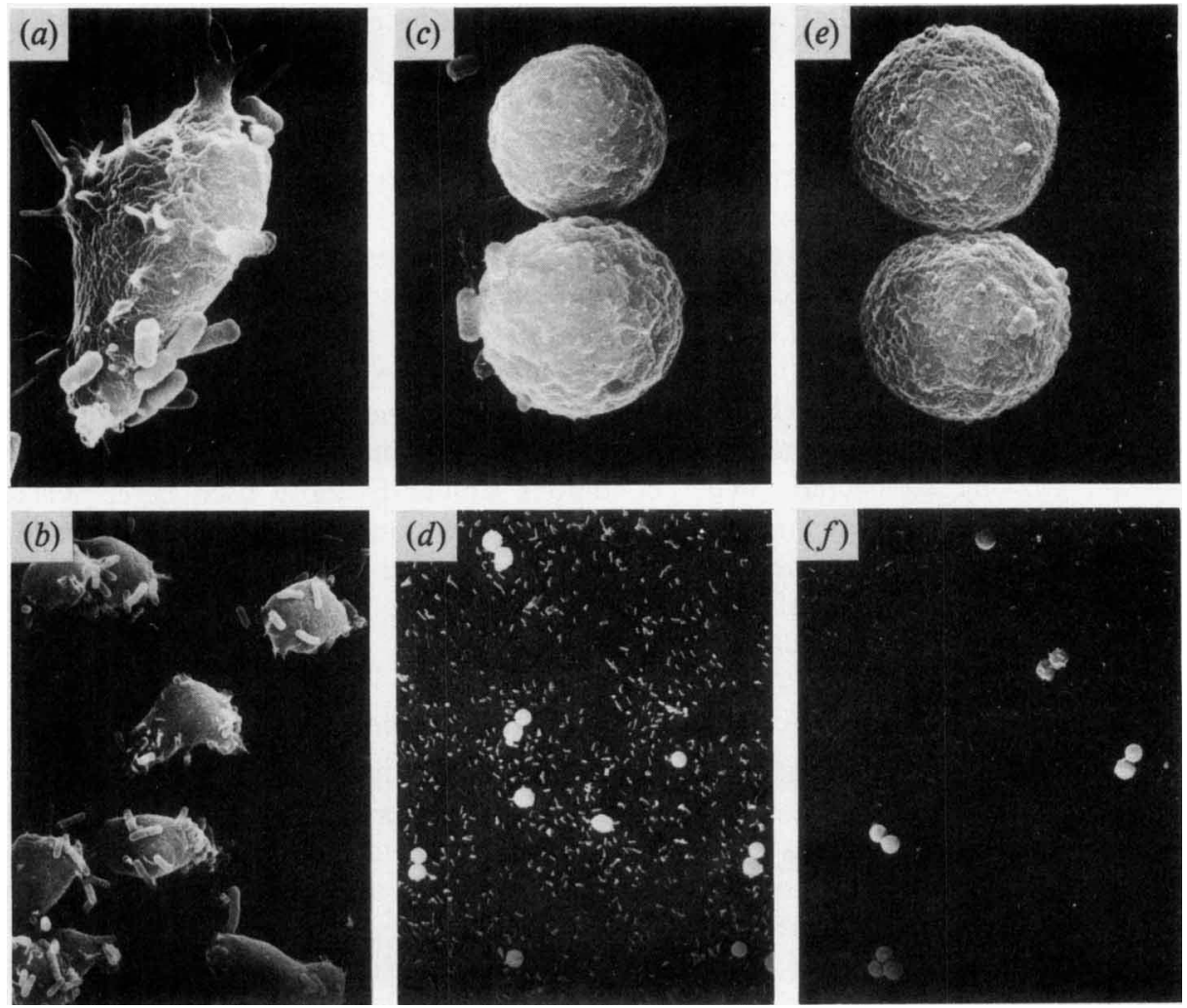

Fig. 2. Scanning electron micrographs of cells of wild-type strain HU526: untreated control $(a, b)$; treated with $5 \mathrm{mM}$-coumarin for $3 \mathrm{~h}(c, d)$; and treated with $125 \mu \mathrm{g}$ thiabendazole $\mathrm{ml}^{-1}$ for $3 \mathrm{~h}(e, f)$. The diameters of cells shown are approximately $7 \mu \mathrm{m}$.

concentrations of coumarin. For example, HU413, a couA351 strain, has a doubling time of about $13 \mathrm{~h}$ in the presence of $1.0 \mathrm{mM}$-coumarin and cell division was completely inhibited at $1.6 \mathrm{~mm}$-coumarin, while untreated cultures grew at a rate similar to that of untreated cultures of the wild-type strain HU526 (Fig. $1 b$ ).

\section{Cell-cell adhesion of vegetative cells in the presence of coumarin and mitotic inhibitors}

At coumarin concentrations which completely inhibited cell division, the cells appeared more refractile and spherical than untreated cells when observed by light microscopy. In addition, the cells of wild-type strains and of most coumarin-sensitive mutants adhered to each other in the presence of coumarin at concentrations that completely inhibited cell division (Table 7). Groups of two to more than ten cells were seen but most cells were in pairs. The extent of cell-cell adhesion (percentage of cells involved, number of cells per group, rate of group formation etc.) was dependent on drug concentration. The drug concentrations used to obtain the data presented in Table 7 were chosen as the lowest to give reproducible cell-cell adhesion within about $5 \mathrm{~h}$. Scanning electron microscopy of coumarin-treated cells of the wild-type strain HU526 showed that the coumarin-treated cells were spherical and lacked the numerous filopodia seen on untreated cells (Fig. 2). EDTA at a concentration of $1 \mathrm{~mm}$ completely inhibited this cell-cell adhesion. Thus, contact sites $\mathrm{B}$, which are known to exist on vegetative cells and whose interaction is EDTA-sensitive (Gerisch, 1961), may be involved in this phenomenon. The major difference between the coumarin-sensitive mutants 
and wild-type strains was that with the mutants this cell-cell adhesion occurred at lower coumarin concentrations (Table 7).

The only coumarin-sensitive mutant in which cell-cell adhesion was not induced was the couB352 strain, HU609. Instead, the cells of HU609 lysed in the presence of coumarin at concentrations of $1.6 \mathrm{mM}$ or more. HU609 was the only mutant in which this phenotype was encountered. Lysis was also seen on treatment of the wild-type strain HU526 with cambendazole $\left(80-200 \mu \mathrm{g} \mathrm{ml}^{-1}\right)$ and CIPC $\left(50 \mu \mathrm{g} \mathrm{ml}^{-1}\right)$ but not with coumarin (up to $5 \mathrm{~mm}$ ).

Similar cell-cell adhesion occurred when the wild-type strain HU526 was treated with thiabendazole $\left(50-200 \mu \mathrm{g} \mathrm{ml}^{-1}\right)$, cambendazole $\left(80-200 \mu \mathrm{g} \mathrm{ml}^{-1}\right)$ or CIPC $\left(25 \mu \mathrm{g} \mathrm{ml}^{-1}\right)$. In particular, thiabendazole-treated cells appeared identical to coumarin-treated cells in the scanning electron microscope (Fig. 2). At lower concentrations (10,50 and $5 \mu \mathrm{g} \mathrm{ml}^{-1}$, respectively) all three compounds have been shown to induce metaphase arrest in $D$. discoideum growing on bacteria under conditions similar to those used here (Welker \& Williams, $1980 \mathrm{~b}$; unpublished results for CIPC-induced metaphase arrest). In addition, thiabendazole $\left(2 \mu \mathrm{g} \mathrm{m}^{-1}\right)$, cambendazole $\left(10 \mu \mathrm{g} \mathrm{ml}^{-1}\right)$ and CIPC $\left(1 \mu \mathrm{g} \mathrm{ml}^{-1}\right)$ all induce haploidization of diploid cells of $D$. discoideum (Welker \& Williams, $1980 b$; unpublished results for CIPC-induced haploidization).

\section{Cell-cell adhesion at high temperature}

Further evidence that the growth temperature-sensitivity and coumarin-sensitivity of strains carrying $t \mathrm{sg} K 21 / \mathrm{couA} 351$ mutation(s) were due to a single mutation was obtained from suspension cultures incubated at $28^{\circ} \mathrm{C}$ (slightly above the normally used restrictive temperature, $26.5^{\circ} \mathrm{C}$ ) in the absence of coumarin. Under these conditions cells of strain HU413 (tsgK21/couA351) formed cell-cell contacts that appeared identical to those formed at $21{ }^{\circ} \mathrm{C}$ in the presence of coumarin (Table 7). Cells of the coumarin-sensitive, temperature-sensitive strain HU970 (tsgT360/couF354) also formed contacts at $28^{\circ} \mathrm{C}$ (Table 7); thus, the two phenotypes may be associated with a single mutation in this strain also. Such temperature-induced cell-cell adhesion was not observed in either the wild-type strain HU526 or haploids that bore the following temperature-sensitivity mutations: tsgA1 (HU445), $t$ sgD12 (TS12, HU154), $t$ sgE13 (HU154), $t$ sgH353 (M146) and $t$ sgR358 (HU608). Nor was cell-cell adhesion induced at $28{ }^{\circ} \mathrm{C}$ in haploids that carried the couB352 (HU609), couC356 (HU608), couD355 (HU833) or couE353 (HU610) mutations. Thus, the temperature-induced cell-cell adhesion of haploids which carry the $\operatorname{tsg} K 21 / \operatorname{couA351}$ or tsgT360/couF354 mutations appears to be specific to these strains.

\section{Multiple tip formation in pseudoplasmodia treated with coumarin, thiabendazole or cambendazole}

The inhibitors colchicine and CIPC have previously been shown to induce multiple tip formation in pseudoplasmodia of $D$. discoideum (O'Day \& Durston, 1978; White et al., 1981). Coumarin $(1.0-2.0 \mathrm{~mm})$, thiabendazole $\left(30-50 \mu \mathrm{g} \mathrm{ml}^{-1}\right)$ and cambendazole $(80-$ $100 \mu \mathrm{g} \mathrm{ml}^{-1}$ ) all induced multiple tip formation in the wild-type strain HU526 as did CIPC $\left(10 \mu \mathrm{g} \mathrm{ml}^{-1}\right)$.

\section{Lack of evidence for metaphase arrest or haploidization by coumarin}

While coumarin induces some effects like those caused by the mitotic inhibitors thiabendazole, cambendazole, CIPC and colchicine it does not appear to induce metaphase arrest in bacterially grown cells of $D$. discoideum or to induce haploidization. In cells of strain HU526 treated with either 3 or $5 \mathrm{~mm}$-coumarin for $3 \mathrm{~h}$ no metaphase figures were seen, while control cultures had about $2 \%$ metaphase figures and a culture treated with 1 mM-coumarin had $1.5 \%$ metaphase figures (cell division of HU526 is only slightly inhibited at this concentration; Fig. 1a). With HU413 (couA351), untreated control cultures had about $2 \%$ 
metaphase figures, but no metaphase figures were seen after treatment for $3 \mathrm{~h}$ with $1 \cdot 0,1 \cdot 3$, $1 \cdot 6,1.8$ or $2 \cdot 0 \mathrm{~mm}$-coumarin.

Diploid cells of DP1 did not sector haploids on SM agar containing $1.3 \mathrm{mM}$-coumarin. Thus, coumarin does not appear to be a haploidizing agent like benlate, thiabendazole, cambendazole or CIPC. The fact that heterozygous diploids can be selected from mixed populations of coumarin-sensitive parental haploids on media containing $1.3 \mathrm{~mm}$-coumarin is further evidence that coumarin does not induce haploidization (Table 3).

\section{DISCUSSION}

Six coumarin-sensitivity mutations are now known in $D$. discoideum. With the exception of the couC356 mutation which is semi-dominant, these mutations are recessive. Two (couA351 and couF354) are linked to temperature-sensitivities that may be the pleiotropic effects of the coumarin-sensitivity mutations. Exposure to high temperature $\left(28^{\circ} \mathrm{C}\right)$ induced cell-cell adhesion in strains bearing either the couA351 or couF354 mutation similar to that seen on exposure to coumarin. This phenotype was not observed at $28^{\circ} \mathrm{C}$ with strains other than those carrying the couA351 or couF354 mutations. Further evidence for the pleiotropy of the coumarin-sensitivity and temperature-sensitivity of strains carrying the couA351/tsgK21 mutation(s) was obtained with revertants selected on the basis of temperature-resistance. All eleven independently isolated revertants were more coumarin-resistant than their parents. The isolation of temperature-resistant strains which carry a reversion of or suppressor of the tsgK21 mutation and which are also coumarin-resistant strongly implies that the growth temperature-sensitivity and coumarin-sensitivity of strains carrying the couA351/tsgK21 mutation(s) are closely related properties. The simplest interpretation of these results is that the coumarin-sensitivity and growth temperature-sensitivity of strains that carry the couA351/tsgK21 mutation(s) are the pleiotropic effects of a single mutation on linkage group VII. Similar effects have been observed with certain mutations in the gene for $\beta$-tubulin of Aspergillus nidulans which lead simultaneously to benomyl-resistance and temperaturesensitivity (Sheir-Neiss et al., 1978).

Inconsistent with our interpretation of pleiotropy at the couA/tsgK locus are the results of Wallace \& Newell (1982) in which the temperature-sensitivity and coumarin-sensitivity of strains carrying the $\operatorname{tsg} K 21$ and couA351 mutation(s) were apparently separated by mitotic recombination. In order to test whether or not the couA351 and $t s g K 21$ mutations were separated we constructed a diploid between the couA351 tsgK21 haploid HU413 and XP222, a coumarin-sensitive temperature-resistant ( $\operatorname{couA351}$ ? $\left.t \mathrm{sg} \mathrm{K}^{+}\right)$haploid segregant of one of the putative mitotic recombinants, which was kindly sent to us by J.S. Wallace and P. C. Newell. If XP222 carried the couA351 allele, we would not expect to be able to isolate a diploid on the basis of complementation of coumarin-sensitivity mutations between XP222 and a strain containing the couA351 mutation. However, we were able to isolate diploids between HU413 and XP222 by this method. Wallace \& Newell (1982) have confirmed this result by isolating diploids between NP187 and XP222. Our diploid, DU1787, has a plating efficiency of greater than 0.5 on SM agar containing $1.3 \mathrm{mM}$-coumarin, though it does grow more slowly than most other diploids heterozygous for coumarin-sensitivity mutation(s). The diploid of Wallace \& Newell (1982) is similar in phenotype to DU1787. They interpreted their data as indicating that XP222 and NP187 carried the same coumarin-sensitivity mutation. We believe this conclusion is unwarranted. We conclude that XP222 carries a coumarinsensitivity mutation (cou-392) of unknown origin which is not identical to the couA351 mutation. Unfortunately, other haploid segregants of putative recombinants in the presumed couA-tsgK interval were not kept by Wallace \& Newell so it is not possible at the present time to investigate the properties of such strains. Until this is done we feel that the genetic separation of the couA351 and $t s g K 21$ mutations has not been conclusively established. 
There are now four classes of compounds all of which appear to affect the microtubular system of $D$. discoideum. These are colchicine (Cappuccinelli \& Ashworth, 1976; O'Day \& Durston, 1978; Zada-Hames, 1977), benzimidazole derivatives including nocodazole (Cappuccinelli et al., 1979), thiabendazole, cambendazole and benomyl (Welker \& Williams, $1980 \mathrm{~b}$; Williams \& Barrand, 1978), CIPC and related compounds (White et al., 1981; Cappuccinelli \& Ashworth, 1976; this report), and coumarin. Treatment of vegetative cells with coumarin, thiabendazole or CIPC inhibited division, resulted in a loss of filopodia, led to a spherical shape and induced EDTA-sensitive cell-cell adhesion that could reflect the patching of cell surface molecules such as contact sites B. Coumarin, thiabendazole and cambendazole induced multiple tip formation in pseudoplasmodia as did colchicine (O'Day \& Durston, 1978) and CIPC (White et al., 1981).

In addition to these effects on cell shape and pseudoplasmodial organization, colchicine, the benzimidazole derivatives and CIPC inhibit the function of the mitotic spindle. Benzimidazole derivatives and CIPC induced metaphase arrest and haploidization at low doses in $D$. discoideum (Welker \& Williams, $1980 \mathrm{~b}$; White et al., 1981; this report), although benomyl was ineffective at the induction of metaphase arrest in $D$. discoideum but not in another slime mould, Polysphondylium pallidum (Williams, 1980). Colchicine was relatively ineffective at inducing metaphase arrest in D. discoideum (Zada-Hames, 1977) and $P$. pallidum (Williams, 1980). In D. discoideum, coumarin is neither a haploidizing agent nor a mitotic poison; therefore it may not affect the mitotic spindle.

Similar effects on cell shape and cell division to those found in $D$. discoideum have been seen with coumarin-treated cells of Euglena gracilis (Fasulo et al., 1979; Vannini et al., 1977). In E. gracilis, coumarin induced a lengthening of the $G 2$ phase of the cell cycle but cytoplasmic and flagellar microtubules remained visible (Fasulo et al., 1979). Microtubules also remained visible in coumarin-treated protoplasts of the fresh water alga Mougeotia (Marchant, 1979) and in cells of pine seedlings (Itoh, 1976). Fasulo et al. (1979) suggest that coumarin may act by disturbing microtubule organizing centres. Such an activity is not inconsistent with our observations in $D$. discoideum.

We wish to thank Drs G. Gerisch and M. Claviez and Frau A. Röglin for their help with the scanning electron microscopy; Dr S. Kayman for helpful comments; R. Smith, H. Dähne and G. Rüger for technical assistance; and A. Kühnlein for typing the manuscript. We also thank Dr P. C. Newell and Ms J. S. Wallace for the gift of XP222 and the exchange of unpublished results. D.L.W. was supported by a U.S. National Institutes of Health Post-doctoral Fellowship from the National Cancer Institute (F32 CA06162).

\section{REFERENCES}

Cappuccinelli, P. \& Ashworth, J. M. (1976). The effect of inhibitors of microtubule and microfilament function on the cellular slime mould Dictyostelium discoideum. Experimental Cell Research 103, 387393.

Cappuccinelli, P., Fighetti, M. \& Rubino, S. (1979). A mitotic inhibitor for chromosomal studies in slime moulds. FEMS Microbiology Letters 5, 25-27.

Cohen, A. J. (1979). Critical review of the toxicology of coumarin with special reference to interspecies differences in metabolism and hepatotoxic response and their significance to man. Food and Cosmetics Toxicology 17, 277-289.

Cornman, I. (1947). The responses of onion and lily mitosis to coumarin and parasorbic acid. Journal of Experimental Biology 23, 292-297.

Dall'Olio, G. \& Vannini, G. L. (1979). Coumarininduced disturbances of morphological development and cell wall formation in Trichophyton mentagrophytes. European Journal of Cell Biology 18, 390-397.

Deering, R. A., Smith, M. S., Thompson, B. K. \& Adolf, A. C. (1970). Gamma-ray-resistant and -sensitive strains of slime mold (Dictyostelium discoideum). Radiation Research 43, 711-728.

Fasulo, M. P., Vannini, G. L., Bruni, A. \& Dall'Olio, G. (1979). Coumarin as a cytostatic drug for Euglena gracilis. A clue to cell cycle study. Zeitschrift für Pflanzenphysiologie 93, 117-127.

FEUER, G. (1974). The metabolism and biological actions of coumarins. Progress in Medicinal Chemistry 10, 85-158.

Free, S. J., Schimke, R. T. \& Loomis, W. F. (1976). The structural gene for $\alpha$-mannosidase- 1 in Dictyostelium discoideum. Genetics 84, 159-174.

Gerisch, G. (1961). Zellfunktionen und Zellfunktionswechsel in der Entwicklung von Dictyo- 
stelium discoideum. V. Stadienspezifische Zellkontaktbildung und ihre quantitative Erfassung. Experimental Cell Research 25, 535-554.

GrIGG, G. W. (1978). Genetic effects of coumarins. Mutation Research 47, 161-181.

Iтон, I. (1976). Microfibrilla orientation of radially enlarged cells of coumarin- and colchicine-treated pine seedlings. Plant and Cell Physiology 17, 385-398.

Katz, E. R. \& Sussman, M. (1972). Parasexual recombination in Dictyostelium discoideum: selection of stable diploid heterozygotes and stable haploid segregants. Proceedings of the National Academy of Sciences of the United States of America 69, 495-498.

Lush, I. E. \& ANDrews, K. M. (1978). Genetic variation between mice in their metabolism of coumarin and its derivatives. Genetical Research 31, $177-186$.

Marchant, H. J. (1979). Microtubules, cell wall deposition and the determination of plant cell shape. Nature, London 278, 167-168.

Morrissey, J. H., Wheeler, S. \& Loomis, W. F. (1980). New loci in Dictyostelium discoideum determining pigment formation and growth on Bacillus subtilis. Genetics 96, 115-123.

Newell, P. C. (1978). Genetics of the cellular slime moulds. Annual Review of Genetics 12, 69-93.

Newell, P. C., Henderson, R. F., Mosses, D. \& RATNER, D. I. (1977). Sensitivity to Bacillus subtilis: a novel system for selection of heterozygous diploids of Dictyostelium discoideum. Journal of General Microbiology 100, 207-211.

O'Day, D. H. \& Durston, A. J. (1978). Colchicine induces multiple axis formation and stalk cell differentiation in Dictyostelium discoideum. Journal of Embryology and Experimental Morphology 47, 195-206.

O'Reilly, R. A. \& Aggeler, P. M. (1965). Coumarin anticoagulant drugs: hereditary resistance in man. Federation Proceedings 24, 1266-1273.

ÖSTERGREN, G. (1948). Chromosome bridges and breaks by coumarin. Botaniska notiser 4, 376-380.

Ratner, D. I. \& Newell, P. C. (1978). Linkage analysis in Dictyostelium discoideum using multiply marked tester strains: establishment of linkage group VII and the reassessment of earlier linkage data. Journal of General Microbiology 109, 225-236.

Rothman, F. G. \& Alexander, E. T. (1975). Parasexual genetic analysis of the cellular slime mold Dictyostelium discoideum A3. Genetics 80, 715-731.

Sheir-Neiss, G., LAI, M. H. \& Morris, N. R. (1978). Identification of a gene for $\beta$-tubulin in Aspergillus nidulans. Cell 15, 639-647.

Svensson, S. (1971). The effect of coumarin on root growth and root histology. Physiologia plantarum 24, 446-470.
Vannini, G. L., Fasulo, M. P. \& Bruni, A. (1977). First observations on the cytological changes induced in Euglena gracilis by coumarin treatment. Zeitschrift für Pflanzenphysiologie 84, 183-187.

Wallace, J. S. \& Newell, P. C. (1982). Genetic analysis by mitotic recombination in Dictyostelium discoideum of growth and developmental loci on linkage group VII. Journal of General Microbiology 128, 953-964.

WELKER, D. L. \& DEERING, R. A. (1978). Genetics of radiation sensitivity in the slime mould Dictyostelium discoideum. Journal of General Microbiology 109, 11-23.

Welker, D. L. \& Williams, K. L. (1980a). Bacillus subtilis sensitivity loci in Dictyostelium discoideum. FEMS Microbiology Letters 9, 179-183.

Welker, D. L. \& Williams, K. L. (1980 $b$ ). Mitotic arrest and chromosome doubling using thiabendazole, cambendazole, nocodazole and ben late in the slime mould Dictyostelium discoideum. Journal of General Microbiology 116, 397-407.

WelkeR, D. L. \& Williams, K. L. (1980c). The assignment of four new loci, including the coumarin sensitivity locus couA, to linkage group VII of Dictyostelium discoideum. Journal of General Microbiology 120, 149-159.

White, E., Scandella, D. \& Katz, E. R. (1981). Inhibition by CIPC of mitosis and development in Dictyostelium discoideum, and the isolation of CIPC-resistant mutants. Developmental Genetics 2 , 99-111.

Williams, K. L. (1978). Characterization of dominant resistance to cobalt chloride in Dictyostelium discoideum and its use in parasexual genetic analysis. Genetics 90, 37-47.

Williams, K. L. (1980). Examination of the chromosomes of Polysphondylium pallidum following metaphase arrest by benzimidazole derivatives and colchicine. Journal of General Microbiology 116 , 409-415.

Williams, K. L. (1981). Two arsenate resistance loci in the cellular slime mould Dictyostelium discoideum. FEMS Microbiology Letters 11, 317-320.

Williams, K. L. \& Barrand, P. (1978). Parasexual genetics in the slime mould Dictyostelium discoideum: haploidisation of diploid strains using benlate. FEMS Microbiology Letters 4, 155-159.

Williams, K. L. \& Newell, P. C. (1976). A genetic study of aggregation in the cellular slime mould Dictyostelium discoideum using complementation analysis. Genetics 82, 287-307.

WoLF, F. T. (1974). Effects of coumarin upon plant growth and development. Journal of the Tennessee Academy of Science 49, 27-33.

ZADA-HAMES, I. M. (1977). Analysis of karyotype and ploidy of Dictyostelium discoideum using colchicineinduced metaphase arrest. Journal of General Microbiology 99, 201-208. 